\title{
Análise da qualidade de vida de agricultores familiares: estudo de caso em Três Passos, Rio Grande do Sul (RS)
}

\author{
Jean Callai GARCEZ ${ }^{1}$, Danni Maisa da SILVA ${ }^{1 *}$, Aaron Concha Vasquez HENGLES ${ }^{1}$, \\ Divanilde GUERRA ${ }^{1}$, Ramiro Pereira BISOGNIN ${ }^{1}$, Robson Evaldo Gehlen BOHRER ${ }^{1}$
}

\author{
${ }^{1}$ Universidade Estadual do Rio Grande do Sul, Três Passos, RS, Brasil. (Orcid: 0000-0002-3853-496X; *; \\ 0000-0002-7707-8020; 0000-0001-5136-2763; 0000-0002-1052-3521; 0000-0002-2001-8983) \\ *E-mail: danni-silva@uergs.edu.br (Orcid: 0000-0002-3600-0462)
}

Recebido em 13/02/2020; Aceito em 14/07/2020; Publicado em 31/07/2020.

\begin{abstract}
RESUMO: A busca por melhores condições de vida é unânime entre os seres humanos, porém, muitos não conseguem atender as suas necessidades por diferentes motivos. Definir qualidade de vida é algo complexo, por isso, existem diversas possibilidades de classificação, ligadas, também, ao aspecto financeiro, à saúde e ao conforto. As famílias que vivem nas pequenas propriedades rurais, geralmente, apresentam maior vulnerabilidade socioeconômica e precisam de maior atenção das instituições públicas. Diante disto, objetivouse, aqui, estudar as condições de vida de agricultores familiares de Três Passos (RS). Após discussão sobre qualidade de vida, apresentam-se os resultados do estudo de caso realizado com 20 famílias da zona rural do município. Este estudo foi realizado por meio da aplicação de um questionário com questões quali-quantitativas relacionadas à rotina familiar, ao trabalho, à qualidade de vida, às dificuldades, aos benefícios e às perspectivas de sucessão familiar. Os resultados sobre a percepção dos produtores a respeito da qualidade de vida apontaram pontos positivos, relacionados ao fato destes "gostarem de morar no meio rural" e negativos, vinculados, também, às dificuldades de acesso, ao êxodo dos jovens e a dificuldades financeiras. Estes aspectos reforçam a necessidade de novas políticas públicas de auxílio e incentivo ao pequeno produtor.
\end{abstract}

Palavras-chave: Agricultura familiar, sucessão rural, políticas públicas.

\section{Analysis of the quality of life of family farmers: case study from Três Passos, Rio Grande do Sul (RS), Brazil}

\begin{abstract}
The search for better living conditions is unanimous among human beings, however, many are unable to meet their needs for different reasons. Therefore, defining quality of life is complex, so there are several possibilities for classifications, such as in relation to financial aspects, health and comfort. Families that live on small farms in rural areas generally have greater socioeconomic vulnerability and need more attention from public institutions. Given this context, the aim of this study was to study the living conditions of family farmers in Três Passos, RS. After a discussion on conditions and quality of life, the results of the survey carried out with 20 families living in the rural area of a municipality in the Três Passos/RS are presented. This survey was carried out through the application of a questionnaire with quali-quantities related to the family's daily life, work, quality of life, difficulties, benefits and perspective of family succession. The results on the perception of the interviewed producers regarding quality of live pointed out positive points, related to the fact that they "like to live in rural areas" and negative ones, linked, among others, to the difficulties of access, the exodus of young people and difficulties financial. These aspects reinforce the need for new public policies to assist and encourage small producers.
\end{abstract}

Keywords: Family farming, rural succession, public policy.

\section{INTRODUÇÃO}

A agropecuária é indispensável para o mundo, todos dependem desta atividade para obter os alimentos consumidos no dia-a-dia e demais produtos derivados dela. Além disso, muitas pessoas também dependem dela para gerar renda de forma direta ou indireta. Com base na grande importância da atividade agropecuária para o país, o meio rural brasileiro tem sido estudado por meio de dados obtidos no Censo Agropecuário, realizado pelo Instituto Brasileiro de Geografia e Estatística (IBGE, 2017a), que permitem caracterizar a população rural brasileira e levantar elementos pertinentes a sua qualidade de vida. De acordo com Azevedo (2008), definir qualidade de vida é difícil, arriscado e polêmico, devido aos diferentes pontos de vista que cada cultura tem em relação à mesma.

Para Pereira et al. (2012), qualidade de vida relaciona-se com o fato do indivíduo se sentir satisfeito, incluindo, o acesso a oportunidades de ser feliz e de alcançar autorrealização, independentemente de sua saúde, condições sociais e financeiras. Qualidade de vida é uma noção eminentemente humana e abrange muitos significados que refletem conhecimentos, experiências e valores de indivíduos e coletividades (DANTAS et al., 2003). Para Herculano (2000) qualidade de vida é "definida como a soma das condições econômicas, ambientais, científico-culturais e políticas, coletivamente construídas e postas à disposição dos 


\section{Garcez et al.}

indivíduos para que estes possam realizar suas potencialidades: inclui a acessibilidade à produção e ao consumo, aos meios para produzir cultura, ciência e arte, bem como pressupõe a existência de mecanismos de comunicação, de informação, de participação e de influência nos destinos coletivos, através da gestão territorial que assegure água e ar limpos, higidez ambiental, equipamentos coletivos urbanos, alimentos saudáveis e a disponibilidade de espaços naturais urbanos, bem como da preservação de ecossistemas naturais".

Em relação à qualidade de vida no meio rural, é importante e necessário destacar que o Brasil passou por um processo de modernização da agricultura brasileira (Revolução Verde) que, além de uma modificação da base técnica, significou a transnacionalização da agricultura, que se volta para a formação dos complexos agroindustriais e para a modernização dos latifúndios (AGRA; SANTOS, 2001). De acordo com Balsan (2006) e Matos (2010), após a Revolução Verde, as máquinas passaram a ocupar, progressivamente, o lugar dos humanos na agricultura, acarretando em êxodo rural e, consequentemente, drástica redução da população rural brasileira, que migrou para os grandes centros em busca de novas oportunidades. Sendo assim, o processo caracterizou-se como heterogêneo, excludente e parcial, por se concentrar nas regiões Sul, Sudeste e Centro-oeste e nas monoculturas voltadas principalmente para a exportação. Estes passaram a ser um modelo de agricultura bimodal, com áreas de agricultura moderna convivendo com áreas de agricultura tradicional, que causou impactos socioeconômicos e ambientais, com destaque para o aumento da concentração da pobreza no campo e a expulsão do homem da terra (AGRA; SANTOS, 2001).

Durante a Revolução Verde, as culturas de grãos passaram a ter um alto preço de venda e então foram produzidas em grande escala, enquanto pequenos produtores, que não possuíam recursos financeiros para aderir aos pacotes tecnológicos da citada Revolução, seguiram apenas com a produção de subsistência. Acreditase que esses sejam alguns dos aspectos que influenciaram na redução da qualidade de vida na zona rural, associada à utilização excessiva de agrotóxicos, que com o tempo, pode gerar problemas de saúde aos moradores (DOMINGUES et. al., 2004). De acordo com o estudo de Fenzke et al. (2018), a intoxicação é o principal agravo de saúde relacionado à falta e/ou ao mau uso de Equipamentos de Proteção Individual (EPI).

Atualmente, grande parte dos jovens do campo continuam migrando para a cidade em busca de novas oportunidades de trabalho e rendimentos mais estáveis. Em estudo realizado por Rodrigues et al. (2020), para avaliar a percepção dos jovens da comunidade Piau, distrito de Piranhas, Alagoas, sobre os entraves de residir no meio rural na atualidade, a partir de questionários aplicados a 100 indivíduos de escolas da rede estadual, $92 \%$ relataram que se tivessem oportunidade deixavam o campo, por encontrarem dificuldades frente à educação continuada, falta de oportunidades, como emprego, acesso a crédito e terra. Alves; Dayrell (2015) constataram em seu estudo que o principal objetivo dos jovens é "ser alguém na vida" e que isso, para a grande maioria, significa serem reconhecidos, ou exercer um trabalho no qual sejam reconhecidos e respeitados pela sociedade.
Para Herculano (2000), ter uma vida de qualidade não consiste somente no fato de se viver em cenários de perfeitas condições ambientais. O indivíduo deve ter além disso, acesso à educação, saúde e tecnologia contemporânea. Conforme Pessoa; Alchier (2014), as atuais condições de trabalho no Brasil estão se tornando difíceis em relação às jornadas e condições de trabalho e direitos dos trabalhadores, à medida que a globalização avança e o agronegócio domina a agricultura, de modo que tem aumentado o desgaste físico e mental dos trabalhadores rurais. Segundo os mesmos autores, as novas tecnologias desenvolvidas para a agricultura são, em geral, voltadas para o agronegócio, deixando de lado as propriedades rurais familiares, onde o trabalho tem se tornado mais árduo, com longas jornadas, remuneração não condizente com o valor do trabalho e perda de direitos, estando os agricultores familiares nessas condições, mais sujeitos à redução da qualidade de vida.

De acordo com a Declaração Universal dos Direitos Humanos das Nações Unidas (2017), todos temos direito a: procurar um local seguro para viver (Artigo $13^{\circ}$ ); segurança social (Artigo $22^{\circ}$ ); repouso e lazer (Artigo $24^{\circ}$ ); moradia, saúde e alimentação (Artigo $25^{\circ}$ ); educação (Artigo $26^{\circ}$ ); um mundo justo e livre (Artigo $28^{\circ}$ ); e, por fim, ninguém pode nos tirar esses direitos (Artigo $30^{\circ}$ ). Os aspectos citados podem ser considerados como fundamentais para uma boa qualidade de vida. Feitosa et al. (2015) relatam em seu estudo alguns fatores que indicam qualidade de vida para a comunidade estudada, são esses: acesso a serviços básicos, como saúde e educação; boa alimentação; viver bem; entre outros.

Nesse contexto, outros autores (VIANA et al., 2019) concluíram que existem três fatores principais que compõem qualidade de vida: alimentação, acumulação de capital social e capital humano. Sendo assim, foi com base nessa perspectiva, que no presente trabalho objetivou-se estudar as condições de vida de agricultores familiares, no município de Três Passos, Noroeste do Rio Grande do Sul.

\section{MATERIAL E MÉTODOS}

A pesquisa foi realizada no município de Três Passos, localizado na Região Noroeste do estado do Rio Grande do Sul - Brasil, próximo à fronteira com a Argentina $(35 \mathrm{~km})$; que, segundo o Censo Demográfico do Instituto Brasileiro de Geografia e Estatística - IBGE (2010), possui população de cerca de 24.000 habitantes. O município do estudo está localizado em uma área caracterizada pelo bioma Mata Atlântica - (IBGE, 2004) e possui como solos característicos os Latossolos, conforme a Empresa de Assistência Técnica e Extensão Rural (EMATER/RS-ASCAR) (2015). O Município de Três Passos, segundo o IBGE (2017b), possui 1.285 estabelecimentos agropecuários, que ocupam uma área total de 19.513 ha, o que representa uma média geral de 15,18 ha por estabelecimento, sendo, essencialmente constituído por pequenos estabelecimentos rurais agropecuários.

A metodologia empregada foi de estudo de caso, organizado e realizado em duas etapas. A primeira consistiu da elaboração de uma pesquisa bibliográfica sobre a importância da agricultura familiar e dos conceitos associados à qualidade de vida no campo, bem como das características do município estudado. A segunda etapa, por sua vez, consistiu de pesquisa de campo, realizada a partir de entrevistas semiestruturadas contendo 20 questões abertas, 
que foram aplicadas a 20 agricultores familiares. Considerando-se a ênfase do estudo nos aspectos qualitativos, foram entrevistados agricultores de quatro dos seis distritos do município de Três Passos, sendo estes Floresta, Padre Gonzales, Bela Vista e Erval Novo (Figura 1), onde as famílias entrevistadas foram escolhidas de forma aleatória, a partir da chegada do entrevistador no respectivo distrito em que as entrevistas seriam realizadas, com a seleção casual de propriedades rurais a serem visitadas. Após a aplicação da entrevista para uma das famílias do distrito, o entrevistador escolhia outra família.

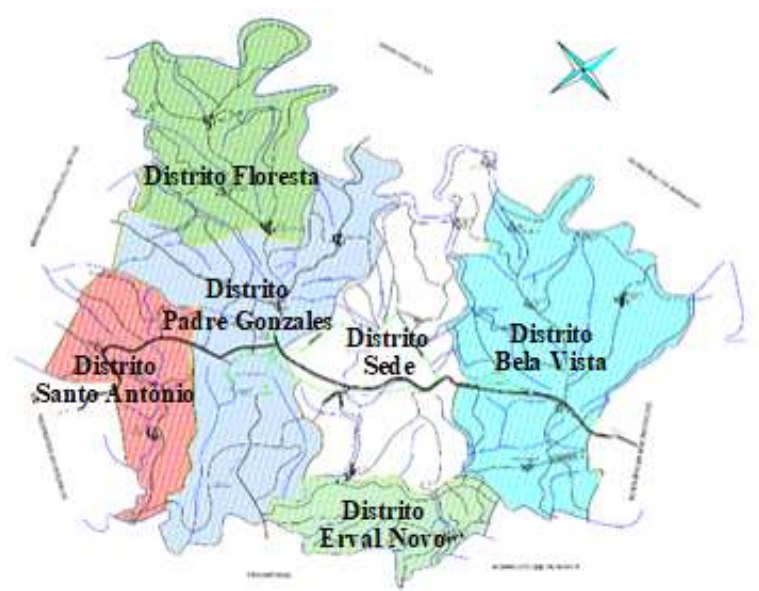

Figura 1. Mapa dos distritos do município de Três Passos/RS, 2017. Fonte: PMTP (2017).

Figure 1. Map of the districts of the municipality of Três Passos/RS, 2017. Source: PMTP (2017).

Para estudar as condições e os aspectos relacionados à qualidade de vida dos agricultores familiares, foram elaboradas questões que envolveram temas relacionados aos seguintes fatores: número de integrantes da família; atividades desenvolvidas na propriedade; disponibilidade de equipamentos e condições de infraestrutura da propriedade e de conforto para a realização do trabalho; condições de realização de trabalho braçal; aspectos financeiros da propriedade (atendimento das demandas mensais da família com os recursos gerados na propriedade); condições de acesso a serviços básicos de saúde, educação, entre outros, bem como sobre a compreensão em relação ao que seria qualidade de vida. Também foram feitas perguntas referentes à forma de trabalho das famílias participantes da pesquisa, iniciando-se pelo questionamento sobre a possível realização de trabalho braçal pesado.

Para evitar a identificação dos entrevistados, as famílias participantes desse estudo foram identificadas, ao longo do texto, por números de 01 a 20. Todas as visitas às propriedades rurais integrantes dessa pesquisa foram realizadas no ano de 2019.

Após a realização das entrevistas, os dados coletados foram organizados, tabulados, analisados e interpretados, fazendo-se considerações e correlações possíveis entre às respostas e também comparações com alguns relatos dos entrevistados.

\section{RESULTADOS}

Entre todas as famílias visitadas, observou-se que o número de integrantes variou entre dois e sete, com oito famílias sendo constituídas por dois integrantes; seis famílias por três integrantes; quatro famílias por quatro integrantes e as outras duas famílias, por cinco e sete integrantes cada.

O tamanho das propriedades pesquisadas variou de 1,3 a 33,5 ha, estando a maioria, na faixa de 10 a 19 hectares. Considerando-se que as dimensões do módulo fiscal do município de Três Passos equivalem a 20 ha, conforme estabelecido pela Instrução Especial/INCRA/nº 20, de 28 de maio de 1980 (BRASIL, 1980), pode-se afirmar que todas as famílias participantes desta pesquisa são de agricultores familiares, sendo que nove dessas famílias possuem estabelecimento agropecuário de até 2 módulos fiscais e as propriedades das outras 11 famílias não excedem 1 módulo fiscal.

Entre as atividades agrícolas das propriedades visitadas, a encontrada com maior frequência foi a produção de grãos, seguida pela produção de subsistência, bovinocultura de leite, criação de frango, produção de fumo e arrendamento, como apresentado na Tabela 1.

Tabela 1. Percentual da distribuição das atividades desenvolvidas nas propriedades pesquisadas, Três Passos/RS, 2019.

Table 1. Percentage of the distribution of activities developed in the surveyed properties, Três Passos/RS, 2019.

\begin{tabular}{lc}
\hline \multicolumn{1}{c}{ Atividade } & \% das propriedades estudadas \\
\hline Grãos & 30 \\
Subsistência & 25 \\
Grãos + Subsistência & 15 \\
Arrendamento & 5 \\
Frangos + Arrendamento & 5 \\
Bovinocultura leiteira & 10 \\
Fumo + Leite & 5 \\
Grãos + Leite + Subsistência & 5 \\
\hline
\end{tabular}

Sobre as atividades realizadas, ressalta-se que seis famílias entrevistadas informaram que gostariam de desenvolver outras atividades, destacando-se a suinocultura (3), a bovinocultura de leite (2), e trabalhar na cidade (1), já as outras 14 famílias não gostariam de desenvolver outra atividade.

Em relação ao maquinário, ou equipamentos existentes nas propriedades, a maioria das famílias (14) afirmou que possuía todos os equipamentos necessários para o desenvolvimento das suas atividades agropecuárias, enquanto que o restante das famílias entrevistadas (6) afirmou não possuir todos os equipamentos necessários, e alegou que isso se dava pela falta de recursos financeiros para adquiri-los. Junto a isso, houve um questionamento sobre o conforto proporcionado pelo uso desses equipamentos, ao qual 19 das 20 famílias afirmaram que os implementos e equipamentos proporcionam conforto a quem está operando, e apenas uma família afirmou o contrário. Ainda assim, metade dos entrevistados (10 famílias) afirmou que realizam trabalho braçal pesado nas atividades desenvolvidas na propriedade.

Os agricultores familiares também foram questionados a respeito das condições de infraestrutura da propriedade, se as benfeitorias para a moradia (casa) atendiam as necessidades das famílias. Em relação a este questionamento a maioria, ou seja, 17 famílias afirmaram que as benfeitorias atendiam as suas necessidades e que não teria necessidade de melhorar a infraestrutura da propriedade (Tabela 2). Por outro lado, três famílias informaram não estarem satisfeitas com as condições das instalações como foi por exemplo, o caso da família " 5 ", em que o entrevistado relatou: "A casa é boa, até agora está servindo, mas precisamos aumentar e fazer algumas reforminhas pra ficar mais bonita e maior". As famílias que não estavam 
satisfeitas com as instalações afirmaram que gostariam de ampliá-las e reformá-las. A Tabela 2 apresenta os dados referentes ao número de famílias que estão ou não satisfeitas com as instalações presentes nas suas propriedades.

Tabela 2. Quantidade de famílias de agricultores satisfeitas e não satisfeitas com a infraestrutura de suas propriedades, Três Passos/RS, 2019.

Table 2. Number of families satisfied and not satisfied with the infrastructure of their properties, Três Passos/RS, 2019.

\begin{tabular}{ccc}
\hline Infraestrutura & Satisfeitos & Não Satisfeitos \\
\hline Casa & 17 & 3 \\
Galpão & 14 & 6 \\
Estábulo* & 8 & 1 \\
\hline *Nem todas as famílias possuíam estábulos, & por & isso o número total \\
apresentado nesse caso é inferior a 20. &
\end{tabular}

No questionamento em que se abordou sobre a quantidade de horas de trabalho diário, a maior parte das famílias, ou seja, nove afirmaram que trabalham por cerca de 12 horas/dia, oito afirmaram trabalhar entre 8 e 10 horas/dia, enquanto que três famílias relataram que trabalham 6,5 e 1 hora/dia, respectivamente.

Quando questionadas se possuíam tudo o que consideram necessário para seu conforto dentro de casa, todas as famílias (20) afirmaram que possuíam tudo o que precisavam. Do mesmo modo, quando questionadas sobre as condições de acesso a serviços como saúde, educação, lazer, deslocamento, esporte, vida em comunidade e tecnologia, todos os entrevistados afirmaram ter boas condições de acesso a todos os serviços elencados. Alguns dos entrevistados, apesar de afirmarem ter boas condições de acesso aos serviços, relataram não ter condições plenas de deslocamento, devido às más condições das estradas, outros relacionaram isso à falta de um veículo próprio ou à falta de transporte público. Estes relatos não foram quantificados como parte da pesquisa pois os entrevistados já haviam respondido que "possuíam boas condições de acesso a tudo", ou seja, que possuíam condições de deslocamento acessíveis até os serviços e o comércio.

\section{DISCUSSÃO}

As famílias com apenas dois integrantes afirmaram que os filhos estão estudando ou já estão formados e residindo em outras cidades ou até mesmo no exterior. Esses dados corroboram com as informações relatadas por Mattei (2014), sobre a ocorrência de êxodo entre as pequenas propriedades do meio rural brasileiro nos últimos anos. Segundo Silva et al. (2019), embora tenha sido dada uma certa relevância à agricultura familiar nos últimos anos, as políticas públicas direcionadas ao setor ainda não são capazes de atender completamente as demandas existentes, de maneira que possam garantir a permanência da população no meio rural, em especial os mais jovens e, diante disso, o êxodo rural ainda está muito presente, reduzindo a população rural.

Aspectos relacionados ao tamanho das propriedades rurais são de fundamental importância para a permanência dos agricultores familiares no campo tendo em vista que o estudo realizado por Hein; Silva (2019), indica que o baixo volume de recursos disponíveis, tais como área pequena, baixos investimentos e nível tecnológico, decorrentes da descapitalização dos agricultores tornam inviável financeiramente a contratação de empregados, ou mesmo manter maior número de membros da família na propriedade para desenvolver as atividades rurais.

Quanto às atividades realizadas (Tabela 1), não se observa uma relação entre tamanho da propriedade e atividades já desenvolvidas e interesse de mudar ou acrescentar atividades ao quadro da propriedade. Durante a visita à propriedade “12”, os entrevistados fizeram a seguinte afirmação: “A gente até queria comeşar a produz̨ir suinos, mas para instalar um chiqueirão é muito caro e não recebemos incentivos para isso". Já durante a visita à propriedade " 5 ", a família afirmou: "A gente queria ter umas vacas de leite, mas os equipamentos são caros, além disso, não temos incentivo e o preço do leite tá muito baixo".

O entrevistado da propriedade " 2 ", foi o único que informou que gostaria de trocar a atividade realizada na propriedade que é a atividade leiteira pelo trabalho na cidade e fez a seguinte afirmação: "Aqui no interior a gente é pouco valorizado, seria melhor trabalhar na cidade”. Este é um aspecto bastante importante uma vez que, segundo Silva et al. (2019), a desvalorização da agricultura familiar é atribuída por alguns autores como um dos motivos para a saída do agricultor do meio rural, sendo muito comum se ouvir palavras ou frases que inferiorizem quem vive na zona rural, o que reforça a decisão, especialmente dos jovens, de deixarem sua vivência no sítio em busca de reconhecimento nas cidades.

Sobre a realização de trabalho braçal pesado, esta característica pode ter uma consequência direta nas condições de vida dos agricultores e agricultoras entrevistadas, e, dependendo da intensidade e do tempo deste trabalho braçal realizado, pode afetar a qualidade de vida dos mesmos. Por outro lado, 50\% dos entrevistados (10 famílias) informaram que não realizam trabalho braçal pesado na propriedade, o que pode contribuir para melhorar a condição de bem estar físico.

Pode-se observar que em estudo relacionado à jornada de trabalho diária de agricultores, já foram encontrados dados semelhantes em diferentes regiões, como informado no estudo de Barth et al. (2016), em que se relatam que a jornada de trabalho dos agricultores entrevistados foi de 9 horas diárias, em média. Nesse sentido, pode-se acrescentar a esta discussão o relato de alguns dos agricultores entrevistados que fizeram uma afirmação muito semelhante uns dos outros: "Aqui nós começamos a trabalhar antes do sol nascer e paramos depois que ele se põe, a vantagem comparado a trabalhar na cidade é que a gente faz nossos horários, podemos começar a trabalhar a hora que quiser, parar para descansar e também terminar o serviço a hora que quiser". Morin (2001) expõe que a forma de trabalhar e o que cada um produz, interferem diretamente na maneira de pensar e perceber a liberdade e independência.

Com relação às condições de conforto no trabalho, Ribas et al. (2003) descreve que o trabalho não está relacionado apenas com questões econômicas, existem também os valores culturais e de autoestima. Tolfo; Piccinini (2007) relatam que, quando trabalhar é visto apenas como uma obrigação e algo necessário somente para a sobrevivência, as pessoas deixam de reconhecê-lo como uma oportunidade de integração, e deixam de se identificar com as atividades executadas.

Como resposta ao questionamento sobre os aspectos financeiros das famílias, em que $80 \%$ delas afirmaram que conseguem atender as suas necessidades, é importante ressaltar que o número de integrantes, o tamanho das propriedades e as atividades nelas desenvolvidas são distintas entre aquelas famílias que afirmaram não conseguir suprir 
suas necessidades com seu rendimento atual, demonstrando então que estes não estão relacionados e não interferiram na resposta da questão. Viana et al. (2019) observaram em seu estudo que os pequenos agricultores tendem a ser eficientes na alocação dos recursos de que dispõem, porém, isso não tem sido o suficiente para se obter uma renda satisfatória, e que isso ocorre na maioria das vezes devido à disponibilidade limitada de outros recursos.

Também é importante discutir sobre as condições de acesso a serviços como saúde, educação, lazer, deslocamento, esporte, vida em comunidade e tecnologia, pois, embora todos os entrevistados tenham afirmado ter boas condições de acesso a todos os serviços elencados, é preciso considerar que nem sempre, na percepção dos entrevistados, as boas condições de acesso a tudo, foram percebidas ou relacionadas com a facilidade de deslocamento, que é determinante para acesso principalmente a mercados e serviços. Em trabalho realizado por Silva et al. (2019), agricultores familiares questionados sobre as causas para a ocorrência do êxodo rural informaram que a falta de infraestrutura e serviços essenciais como hospitais, transporte, escolas, estradas, etc. faz com que as pessoas saiam da zona rural, considerando que estes são fundamentais para garantir o princípio da dignidade da pessoa humana, assim como a inexistência de modernização e tecnologias de produção suficientes e capazes de ampliar a produção e rentabilidade dos agricultores familiares. Por outro lado, considerando-se que o entendimento sobre qualidade de vida permite a exposição de uma compreensão subjetiva, uma agricultora entrevistada, do Assentamento Mulunguzinho em Mossoró, Rio Grande do Norte (RN), relatou que o lugar em que mora a faz feliz, embora reconheça que esse espaço carece de melhor infraestrutura para seus habitantes (MAIA et al., 2017).

Do mesmo modo, apesar de algumas dificuldades relatadas por algumas famílias rurais entrevistadas, ao serem questionadas se gostavam de morar no meio rural, todas afirmaram que sim. Pode-se encontrar algumas justificativas para isso nos relatos dos próprios agricultores entrevistados, tais como do agricultor "8" que explicou o porquê de gostar de viver no interior com a seguinte fala: "Nossos pais vieram de Ijuí pra cá a muitos anos atrás, de carroça e trazendo só o necessário, eles foram pioneiros aqui na região, quando chegaram aqui era tudo mato, nós fizemos parte dessa bistória porque a gente ajudava eles a abrir campos e também no plantio e colheita, nos acostumamos assim, pegamos amor pela terra, pelo interior e agora, com a idade que estamos, não pretendemos sair daqui".

Em busca de um novo emprego, melhores salários, estudos e qualidade de vida, muitos brasileiros migram de um lugar para outro. Nos últimos 50 anos, o êxodo rural cresceu 45,3\% no Brasil (HARTWIG, 2013), sendo essa a realidade comumente vista no cenário rural brasileiro. Entretanto, entre as famílias rurais que participaram desta pesquisa, praticamente a metade, ou seja, 11 famílias apresentam jovens que desejam continuar na propriedade rural. Quando estes jovens foram questionados sobre o interesse em permanecer nas propriedades a maioria dos 11 , ou seja cinco, afirmaram que tem interesse em permanecer porque gostam, enquanto que outros dois afirmaram que possuem esse interesse em função do bom retorno financeiro que podem obter na propriedade rural. Um dos jovens afirmou que gostaria de seguir na propriedade para ser "o dono do próprio negócio" e o restante não soube responder. No entanto, um dos jovens da propriedade "9" afirmou: "Não quero ficar na propriedade porque não gosto de morar pra fora e porque o agricultor não é valorizado, na cidade a gente tem mais oportunidades". Em trabalho realizado por Maia et al. (2017), alguns agricultores entrevistados afirmaram que o preconceito ainda existente com as pessoas que residem no campo, a existência de fatores "atrativos" oferecidos nas cidades como empregos, lazer, esporte e cultura são fundamentais para estimular a migração para a cidade, especialmente dos jovens. Os autores destacam ainda como um motivo importante para o êxodo rural declarado entre os agricultores pesquisados, a qualidade e/ou indisponibilidade de ensino, já que na zona rural a disponibilidade de estudos é limitada e as pessoas buscam nos centros urbanos as condições para educar-se.

O êxodo rural dos jovens pode ainda estar relacionado a questões como as abordadas por Monteiro (2004), que afirma que os jovens tem o trabalho agrícola como algo sofrido. Brumer (2004) acredita que a troca do rural pelo urbano seja influenciada pelos meios de comunicação e transporte, que trazem maior contato da população rural com a cidade. Outra característica que influencia diretamente na permanência do jovem no campo, segundo Gaviria; Pezzi (2007), está relacionada ao fato de que muitos pais não querem que seus filhos sejam agricultores devido ao trabalho árduo, falta de recursos para investimentos, entre outros.

Dificuldades fazem parte do dia a dia de muitas famílias, porém, as famílias que residem no interior possuem algumas dificuldades diferentes das famílias urbanas. No presente estudo, $20 \%$ das famílias alegaram não ter dificuldades, enquanto que as $80 \%$ restantes elencaram alguns pontos de dificuldades, tais como a da falta de mão de obra. Neste sentido, quatro produtores reclamaram da falta de pessoas para o trabalho no campo e ainda informaram que a maioria dos trabalhadores que são contratados, não fica por muito tempo na propriedade. Outra dificuldade mencionada foi relacionada ao preço dos insumos utilizados nas propriedades rurais e o preço de venda dos produtos, como relata um dos entrevistados da propriedade "2": "Ultimamente tá sobrando pouco, porque os insumos estão cada vez. mais caros e o que a gente produz nunca aumenta o preço, pelo contrário, as vezes até diminui". Comparado ao estudo realizado por Barth et al. (2016), os agricultores entrevistados reclamaram do trabalho sob sol e chuva, além dos baixos preços dos produtos, o que reflete pontos em comum, mas também diferentes pontos de vista entre os trabalhadores.

Outra dificuldade relatada pelos entrevistados foi a falta de apoio por parte dos governantes, aos agricultores, de modo que, muitos alegaram que estão "esquecidos" pelo governo, assim como relatado por um dos entrevistados na propriedade "5": "O governo só faz coisas para os grandes e esquece dos pequenos". Além disso, foram relatadas outras dificuldades, tais como problemas e discordâncias entre a família, a necessidade de realização de trabalho braçal, as más condições das estradas rurais, a distância da propriedade até a cidade e o difícil acesso às máquinas da prefeitura.

Por outro lado, também foram elencados alguns dos principais benefícios de se viver no meio rural, sob o ponto de vista dos agricultores entrevistados. Sobre este aspecto, o benefício mais citado entre todas as famílias foi o sossego, seguido pelo fato de se saber a procedência dos alimentos consumidos na propriedade, além de terem acesso a praticamente tudo o que precisam para a subsistência da família, dependendo pouco do supermercado. Nesse sentido, também foi citada a redução de despesas e o contato com a terra, bem como o fato de poderem organizar o próprio horário de trabalho e, a qualidade de vida. No trabalho 
realizado por Barth et al. (2016), os agricultores entrevistados também elencaram, entre os pontos positivos de se viver no meio rural, a liberdade de estabelecerem os próprios horários de trabalho e o contato com a terra.

Quando os agricultores participantes desta pesquisa foram questionados se acreditavam que tinham qualidade de vida, apenas uma das famílias disse não ter qualidade de vida de forma completa. No entanto, a família não soube responder o que seria necessário para melhorar a qualidade de vida deles, de modo que, não é possível fazer ponderações a respeito disso. Porém, pode-se fazer uma correlação com as respostas dos integrantes dessa família a duas perguntas anteriores, . A primeira está relacionada ao fato de que esta família afirmou que não consegue atender todas as suas necessidades em termos financeiros durante o mês. A segunda pode estar associada à resposta dada ao questionamento sobre o que não é qualidade de vida para a família, a qual respondeu que era a falta de tempo para si. Todas as demais famílias (19) responderam que possuem qualidade de vida. Os argumentos aqui apresentados corroboram com as considerações de Maia et al. (2017), que afirmam que a qualidade de vida não consiste apenas naquilo que é determinado como necessidades básicas, mas também ao que os agricultores familiares almejam no que diz respeito aos medos, sonhos e perspectivas.

Em relação ao entendimento dos entrevistados sobre o que é não ter qualidade de vida, além de não ter tempo pra si mesmo como afirmaram duas famílias, também foram citadas a falta de saúde por oito entrevistados, difícil acesso a serviços básicos (um entrevistado), não ter o que precisa para sobreviver (três entrevistados) e ter dívidas (três entrevistados), o restante (três) não soube responder à pergunta.

Em estudo realizado no município de Farias Brito, Ceará (CE), Feitosa et al. (2015) destacaram alguns fatores que indicavam qualidade de vida para a comunidade estudada, $10 \%$ das famílias residentes na localidade Nova Betânia afirmaram que ter saúde é o principal indicativo de qualidade de vida, porém, $87 \%$ afirmaram que qualidade de vida é uma junção de vários fatores como saúde, educação, boa alimentação, moradia, entre outros.

Já no estudo de Bortolotto et al. (2018), fatores como ser mulher, ter idade avançada, não ser branco, possuir baixa renda, pouca escolaridade, residir a vida toda na zona rural, desemprego e possuir alguma doença foram os mais relevantes para definir de forma negativa a qualidade de vida.

No último questionamento feito foi sobre o que era necessário para melhorar a qualidade de vida da família, a maioria delas, ou seja, 12 famílias responderam que não precisavam de nada para melhorar a sua qualidade de vida. Porém, o restante das famílias elencaram alguns pontos como valorização do produtor, se aposentar, receber melhor pelos seus produtos, mais incentivos ao pequeno produtor e alguém para ajudar na propriedade. Segundo Floriano (2009), a característica mais importante para melhorar a qualidade de vida da população rural está associada a elaboração e implantação de políticas públicas adequadas, que possam reduzir a migração do campo para a cidade e as desigualdades sociais.

Em síntese, para finalizar, a maioria das famílias entrevistadas informou que gosta de viver no meio rural, possui conforto no trabalho e que os seus rendimentos financeiros mensais são suficientes para atender as suas necessidades, de modo que consideram ter qualidade de vida. Os que relataram não possuir qualidade de vida, mencionaram a falta de saúde, de acesso a serviços básicos e o fato de estar endividado como os principais aspectos relacionados à falta de qualidade de vida.

\section{CONSIDERAÇÕES FINAIS}

O desenvolvimento do presente trabalho possibilitou ampliar o conhecimento sobre as condições de vida de famílias de pequenos agricultores do município de Três Passos, no RS, e pode-se observar que algumas famílias gostariam de acrescentar atividades ao quadro da propriedade, porém enfrentam dificuldades financeiras e, ao tentar acessar recursos de crédito para reverter isso, não recebem incentivos governamentais como acesso a políticas públicas relacionadas a linhas de créditos ou subsídios. Outro ponto importante diz respeito às condições de trabalho, que foram relatadas como boas pelas famílias entrevistadas, tendo em vista que $50 \%$ não realiza trabalho braçal pesado, a maioria afirma que possui conforto no trabalho e todos os equipamentos necessários para realizar as atividades.

Pode-se ressaltar que há uma quantidade considerável de jovens que têm interesse em continuar trabalhando nas propriedades rurais das famílias que participaram deste estudo, ou seja, 55\% das famílias apresentaram jovens que têm o desejo de continuar na propriedade, e isso pode estar relacionado às condições de vida relatadas pelos entrevistados.

Por fim, sugere-se a realização de estudos mais aprofundados e mais amplos sobre as condições de vida das famílias rurais, envolvendo maior número de agricultores e de municípios, com o intuito de determinar quais são os principais problemas enfrentados por estas famílias, assim como quais as potencialidades que poderiam contribuir para a melhoria da qualidade de vida das famílias de agricultores.

\section{REFERÊNCIAS}

AGRA, N. G.; SANTOS, R. F. D. Agricultura brasileira: situação atual e perspectivas de desenvolvimento. In: Congresso da Sociedade brasileira de Economia e Sociologia Rural, 39., 2001, Recife. Anais... Recife, 2001. não paginado.

ALVES, M. Z.; DAYRELL, J. Ser alguém na vida: um estudo sobre jovens do meio rural e seus projetos de vida. Educação e Pesquisa, São Paulo, v. 41, n. 2, p. 375-390, 2015. DOI: http://dx.doi.org/10.1590/s151797022015021851

BALSAN, R. Impactos decorrentes da modernização da agricultura brasileira. CAMPO-TERRITÓRIO: revista de geografia agrária, Uberlândia, v. 1, n. 2, p. 123-151, ago. 2006.

BARTH, M.; SIDEGUM, J. R.; NUNES, M. F.; SANFELICE, G. R. Características do trabalho na agricultura familiar e sua influência na emigração dos jovens. Iluminuras, Porto Alegre, v. 17, n. 41, p. 256276, 2016. DOI: https://dx.doi.org/10.22456/19841191.64569

BORTOLOTTO, C. C.; MOLA, C. L.; TOVORODRIGUES, L. Qualidade de vida em adultos de zona rural no Sul do Brasil: estudo de base populacional. Revista Saúde Pública, São Paulo, v. 52, n. supl 1, p. 1-11, 2018. DOI: 
https://dx.doi.org/10.11606/S1518-

8787.2018052000261

BRASIL. Instrução Especial/INCRA/n $\mathbf{n}^{\circ} 20$, de 28 de maio de 1980. Estabelece o Módulo Fiscal de cada Município, previsto no Decreto $n^{\circ} 84.685$, de 06 de maio de 1980. 1980. Disponível em: http://www.incra.gov.br/sites/default/files/uploads/in stitucionall/legislacao--/atos-

internos/instrucoes/ie20_280580.pdf. Acesso em: 11 de mai. 2020.

BRUMER, A. Gênero e Agricultura: a situação da mulher na agricultura do Rio Grande do Sul. Estudos Feministas, Florianópolis, v. 12, n.1, p. 205-227, jan./abr. 2004. DOI: http://dx.doi.org/10.1590/S0104-026X2004000100011

DANTAS R. A. S.; SAWADA, N. O.; MALERBO M. B. Pesquisas sobre qualidade de vida: Revisão da produção cientificas das universidades públicas do Estado de São Paulo. Revista Latino-Americana de Enfermagem, Ribeirão Preto, v. 11, n. 4, p. 532-538, 2003. DOI: http://dx.doi.org/10.1590/S0104-11692003000400017

Declaração Universal dos Direitos Humanos das Nações Unidas. 2017. Disponível em: <www.ohchr.org/EN/UDHR/Documents/UDHR_Tr anslations/por.pdf $>$ Acesso em: 22 de setembro de 2017.

EMATER-RS/ASCAR_GOVERNO DO ESTADO DO RIO GRANDE DO SUL. Atlas Socioeconômico do Estado do Rio Grande do Sul. 2015. Disponível em: < https://atlassocioeconomico.rs.gov.br/solos $>$ Acesso em: 16 de dezembro de 2019.

FENZKE, M. N.; MELLO, M. C. V. A.; SANTOS, K. N. S. C.; CEZAR-VAZ, M. R. Adoecimentos e fatores relacionados à saúde do trabalhador rural. Journal of Nursing, Recife, v. 12, n. 7, p. 2214-2226, 2018. DOI: https://dx.doi.org/10.5205/1981-8963-

v12i8a231532p2214-2226-2018

FEITOSA, H. O.; SILVA, J. A. S.; SILVA, K. V.; SANTOS, R. V. Qualidade de vida das pessoas na zona rural da Nova Betânia de Farias Brito-CE. Ágora: Revista de Divulgação Científica, Mafra, v. 20, n. 2, p. 64-83, 2015. DOI: https://dx.doi.org/10.24302/agora.v20i2.942

FLORIANO, C. O. Identificação da Qualidade de Vida no Meio Rural do Município de Major Vieira. Ágora: Revista de Divulgação Científica, Mafra, v. 16, n. 1, p. 99-107, 2009.

GAVIRIA, M. R.; PEZZI, S. M. O poder simbólico da renda na mobilização social de jovens de comunidades rurais. In: MENASCHE, R. (Org.). A agricultura familiar à mesa: saberes e práticas da alimentação no Vale do Taquari. 1. ed. Porto Alegre, RS: UFRGS, 2007. p. 198.

HARTWIG, M. Migração campo cidade: trajetórias de vida, trabalho e escolarização de jovens trabalhadores. I Seminário Regional de Educação do Campo, 2013. Disponível em: <http://coral.ufsm.br/sifedocregional/> Acesso em: 16 de novembro de 2019.

HEIN, A. F.; SILVA, N. L. S. A insustentabilidade na agricultura familiar e o êxodo rural contemporâneo. Estudos Sociedade e Agricultura, Rio de Janeiro, v. 27, n. 2, p. 394-417, 2019. DOI: https://dx.doi.org/10.36920/esa-v27n2-8

HERCULANO, S. C. A qualidade de vida e seus indicadores. In: HERCULANO; PORTO, M. F. de S.; FREITAS, C. M. de (org.). Qualidade de Vida e Riscos Ambientais. Niterói: Eduff, 2000. p. 219-246.
IBGE_INSTITUTO BRASILEIRO DE GEOGRÁFIA E ESTATISTICA. Censo Agro 2017. 2017a. Disponível em:< https://censos.ibge.gov.br/agro/2017/ >Acesso em: 25 de novembro de 2019.

IBGE_INSTITUTO BRASILEIRO DE GEOGRÁFIA E ESTATISTICA. Censo Agro 2017. 2017b. Disponível em: $\quad<$ https://cidades.ibge.gov.br/brasil/rs/trespassos/pesquisa/24/27745>. Acesso em: 11 de mai de 2020.

IBGE_INSTITUTO BRASILEIRO DE GEOGRÁFIA E ESTATISTICA. Censo Demográfico 2010. 2010. Disponível em:< https://censo2010.ibge.gov.br/ > Acesso em: 15 de novembro de 2019.

IBGE_INSTITUTO BRASILEIRO DE GEOGRÁFIA E ESTATISTICA. IBGE CIDADES. 2004. Disponível em:< https://cidades.ibge.gov.br/brasil/rs/trespassos/panorama > Acesso em: 15 de novembro de 2019.

MAIA, Z. M. G.; SIQUEIRA, E. S.; ROZENDO, C. Desenvolvimento local e Qualidade de vida na percepção de agricultoras no Assentamento Mulunguzinho em Mossoró-RN. Polis, Santiago, v. 16, n. 46, p. 295-319, 2017. DOI: http://dx.doi.org/10.4067/S071865682017000100295

MATOS A. K. V. Revolução Verde, biotecnologia e tecnologias alternativas. Cadernos da FUCAMP, Monte Carmelo, v. 10, n. 12, p. 1-17, 2010.

MATTEI, L. O papel e a importância da agricultura familiar no desenvolvimento rural brasileiro contemporâneo. Revista Econômica do Nordeste, Fortaleza, v. 45, n. 5, p. 83-92, 2014.

MONTEIRO, J. C. O processo de trabalho e o desencadeamento dos agravos à saúde dos trabalhadores rurais: um estudo ergonômico na agricultura familiar em Santa Catarina. 2004. 182f. Tese (Doutorado em Eng. de Produção e Sistemas). Universidade Federal de Santa Catarina, Florianópolis, 2004.

MORIN, E. M. Os sentidos do trabalho. Revista de Administração de Empresas, São Paulo, v. 41, n. 3, p. 8-19, 2001. DOI: http://dx.doi.org/10.1590/S003475902001000300002

PEREIRA, E. F.; TEIXEIRA, C. S.; SANTOS, A. Qualidade de vida: abordagens, conceitos e avaliação. Revista Brasileira de Educação Física e Esporte, São Paulo, v. 26, n. 2, p. 241-250, 2012. DOI: http://dx.doi.org/10.1590/S1807-55092012000200007

PESSOA, Y. S. R. Q.; ALCHIER J. C. Qualidade de vida em agricultores orgânicos familiares no interior Paraibano. Psicologia: Ciência e Profissão, Brasília, v. 34, n. 2, p. 330-343, 2014. DOI: http://dx.doi.org/10.1590/19823703001095012

PMTP_PREFEITURA MUNICIPAL DE TRÊS PASSOS. Site da Prefeitura Municipal de Três Passos. 2017. Disponível em <http://www.trespassos-rs.com.br/> Acesso em: 24 de out. 2017.

RIBAS, J. M. B.; TOMÁS, M. J. E.; DURÁN, C. G.; ARTILES, A. M. Teoría de las relaciones laborales: fundamentos. Barcelona: UOC, 2003. 165 p.

RODRIGUES, M. T. A.; ARAÚJO, C. A.; LIMA, D. O.; LIMA, C. M. D. Éxodo Rural: perspectivas dos jovens sobre a vivencia em meio rural. Diversitas Journal, Bebedouro, v. 5, n. 2, p. 729-738, 2020. DOI: https://dx.doi.org/10.17648/diversitas-journal-v5i2-777 


\section{Garcez et al.}

SILVA, S. S.; ANTONIAZZI, E. A.; NOVAK, M. A. L. O Pronaf como instrumento de fixação do agricultor familiar no campo, evitando o êxodo rural. Desenvolvimento Socioeconômico em Debate, Criciúma, v. 5, n. 2, p. 66-93, 2019.

TOLFO, S. R.; PICCININI, V. Sentidos e significados do trabalho: explorando conceitos, variáveis e estudos empíricos brasileiros. Psicologia \& Sociedade, Porto Alegre, v. 19, n. spe, p. 38-46, 2007. DOI: http://dx.doi.org/10.1590/S0102-71822007000400007

VIANA, L. S.; GUERRERO, S. J.; RAGGI, L. A.; VASCONCELOS BARROS, E. Qualidade de vida no meio rural brasileiro: o caso do sertão de Alagoas. Revista de Economia e Sociologia Rural, Brasília, v. 18, n. 2, p. 181-204, 2019. 